\title{
Heavy metal in radiology: how to reliably differentiate between lodged copper and lead bullets using $\mathrm{CT}$ numbers
}

Dominic Gascho ${ }^{1 *}$ DD, Niklaus Zoelch ${ }^{1,2}$, Henning Richter ${ }^{3}$, Alexander Buehlmann ${ }^{4}$, Philipp Wyss ${ }^{4}$, Michael J. Thali ${ }^{1}$ and Sarah Schaerli, ${ }^{1,5}$

\begin{abstract}
Background: The in situ classification of bullets is of interest in forensic investigations when the bullet cannot be removed. Although computed tomography (CT) is usually performed on shooting victims, visual assessment, or caliber measurements using $C T$ can be challenging or infeasible if the bullets are deformed or fragmented. Independent from the bullet's intactness, $x$-ray attenuation values ( $C T$ numbers) may provide information regarding the material of the bullet.

Methods: Ethical approval was not required (animal cadavers) or waived by the ethics committee (decedents). Copper and lead bullets were fired into animal cadavers, which then underwent $C$ scanning at four energy levels $(80,100,120$, and $140 \mathrm{kVp}$ ). $C T$ numbers were measured within regions of interest (ROls). In addition to comparing $C T$ numbers, the dualenergy index (DEl), representing the ratio between the $C T$ numbers of two energy levels, was calculated. The most appropriate method was applied for decedents with fatal gunshot wounds.

Results: CT numbers demonstrated no significant difference between copper and lead bullets, and false classifications can easily occur. DEl calculations revealed significant differences between the two groups of bullets. The 120/140 DEls calculated from the maximum CT numbers obtained from ROls at the edge of copper versus lead bullets presented a significant difference $(p=0.002$ ) and a gap between the $C T$ numbers of copper and lead bullets and was successfully applied for the decedents.
\end{abstract}

Conclusions: This study presents a viable method for distinguishing copper and lead bullets in situ via CT and highlights the potential pitfalls of incorrect classifications.

Keywords: Copper, Forensic ballistics, Lead, Tomography (x-ray computed), Wounds (gunshot)

\section{Key points}

- Computed tomography (CT) numbers are not reliable for distinguishing copper from lead bullets.

- The dual-energy index (DEI), representing the ratio between the CT numbers of two energies, is more reliable for classifying those bullets.

\footnotetext{
* Correspondence: dominic.gascho@irm.uzh.ch

${ }^{1}$ Department of Forensic Medicine and Imaging, Institute of Forensic Medicine, University of Zurich, Winterthurerstrasse 190/52, CH-8057 Zurich, Switzerland

Full list of author information is available at the end of the article
}

- The ratio of maximum CT numbers $\left(\mathrm{DEI}_{\max }\right)$ was suitable for classifications.

- Using the $120 / 140 \mathrm{DEI}_{\max }$ from CT numbers of bullets' edges is recommended.

\section{Background \\ Computed tomography $(\mathrm{CT})$ allows identification of the location of a lodged projectile and detection of gunshot residues indicating a contact shot $[1,2]$. Ballistic experts examine bullets secured at a crime scene or removed from a body, and laboratory analysis of the deposits from an entrance wound can provide information on the bullet used [3-5]. The in situ identification of a bullet}


can be particularly interesting in forensic investigations [6-8] when a lodged bullet will not be removed from the patient, for example, to avoid the risk of neural damage due to an intervention [9]. The feasibility of visual assessment or caliber measurement of lodged bullets using CT was assessed on real shooting victims in postmortem studies [10-12]. The authors of these studies concluded that visual assessments and caliber measurements on CT are often impeded or infeasible since lodged bullets are frequently heavily deformed or fragmented [13-16]. Therefore, a method that is less dependent on the intactness of a lodged bullet is desired.

Dual-energy-based material differentiation of bullets using clinical CT scanners was assessed in ex situ, animal cadaver, and phantom studies [17-19]. The x-ray attenuation of a material can be measured as CT numbers (Hounsfield unit (HU) values) within a defined region of interest (ROI) including several pixels/voxels. Calculation of a bullet's dual-energy index (DEI) from CT numbers measured at two different energy levels (dual-energy) was recently presented as a robust method for distinction between intact bullets composed of copper (and zinc) and those composed of lead, which were manually inserted into animal cadaver models [18]. Repeated single-energy CT scans at different energy levels were performed instead of actual dual-energy CT scans, since only single-energy CT scans allowed for reconstructions that enabled CT number measurements beyond the standard range of $\mathrm{HU}$ values [18]. Therefore, this DEI method is feasible using any standard CT scanner, but it causes additional radiation exposure. However, previous ex situ studies on foreign bodies demonstrated significantly different CT numbers between copper or brass (a copper-zinc alloy) specimens and lead specimens at a single energy of 130 $\mathrm{kVp}$ [20, 21]; thus, the DEI method might be superfluous for the distinction between copper and lead bullets. Therefore, further investigation of the x-ray attenuation characteristics of copper and lead bullets and exploration of the potential benefit of using the DEI compared to using CT numbers for the differentiation of these two types of bullets were deemed necessary.

This study aimed (1) to investigate the need for two CT scans at different energy levels for the material differentiation of lodged bullets composed of copper and lead in an animal cadaver study and (2) to present a reliable and valid method for differentiating between these two types of frequently encountered bullets using clinical CT scans.

\section{Methods}

No animals were killed for the scientific purposes of this study. The animal models used in this study were obtained from an institute of veterinary pathology. Fresh cadavers were used as an addition to another study with ethical approval and are in accordance with the 3Rs (replacement, reduction, and refinement)-the guiding principles for the ethical use of animals in science. Additional ethical approval for using these animal cadavers was not required. Parts of this study were performed with human cadavers. Ethical approval was waived by the responsible ethics committee of the Canton of Zurich (waiver number: 2015-0686). This article does not contain any studies with (living) human participants.

\section{Animal cadaver study and real forensic cases}

Bullets $(n=12)$ from four different types of ammunition were selected for this study (Action 4, $n=3$; QD-PEP, $n$ = 3; Hydra-Shok, $n=3$; 7.65 Browning, $n=3$ ) (Fig. 1). The bullets were divided into two groups according to their core materials. One group (copper group, $n=6$ ) included the unjacketed Action 4 and QD-PEP bullets, which are composed of copper. These solid copper bullets are deformation bullets that were developed for law enforcement units. The other group (lead group, $n=6$ ) included the Hydra-Shok and 7.65 Browning bullets, which are frequently encountered lead bullets with jackets composed of copper-zinc alloys (copper/zinc). The Hydra-Shok bullet is a semi-jacketed hollow-point (deformation) bullet, while 7.65 Browning bullets (which are also referred to as .32 $A C P$ bullets) are full metaljacketed bullets. From each type of ammunition, three bullets were fired into animal cadaver models at a dedicated shooting range. Sheep legs were used as a substitute for human tissue. The shootings were performed by a ballistics expert from a forensics institute. After shooting, each sheep leg was scanned by CT.

Additionally, the distinction between copper and lead bullets was assessed in real forensic cases with fatal gunshot wounds and lodged bullets. The decedents $(n=15)$ underwent postmortem imaging as part of forensic judicial investigations. Ethical approval was waived by the responsible ethics committee. The bullets were removed during autopsy and identified by the forensics institute. Before the bullets were removed, the decedents underwent a CT examination using the same scanner used for the animal cadaver study. The CT scan protocol from the animal cadaver study was used. Decedents with a lodged Action 4 copper bullet $(n=3)$ and decedents with a lodged .22 $L R$ lead bullet $(n=3)$ were selected for this study.

\section{Scan protocol}

Repeated CT scans using energy levels of 80, 100, 120, and $140 \mathrm{kVp}$ were performed using a standard medical 128-slice CT scanner (SOMATOM Definition Flash, Siemens Healthcare GmbH, Forchheim, Germany). The tube current was adjusted to gain an almost equal volume CT dose index of 9 mGy at each energy level, which 


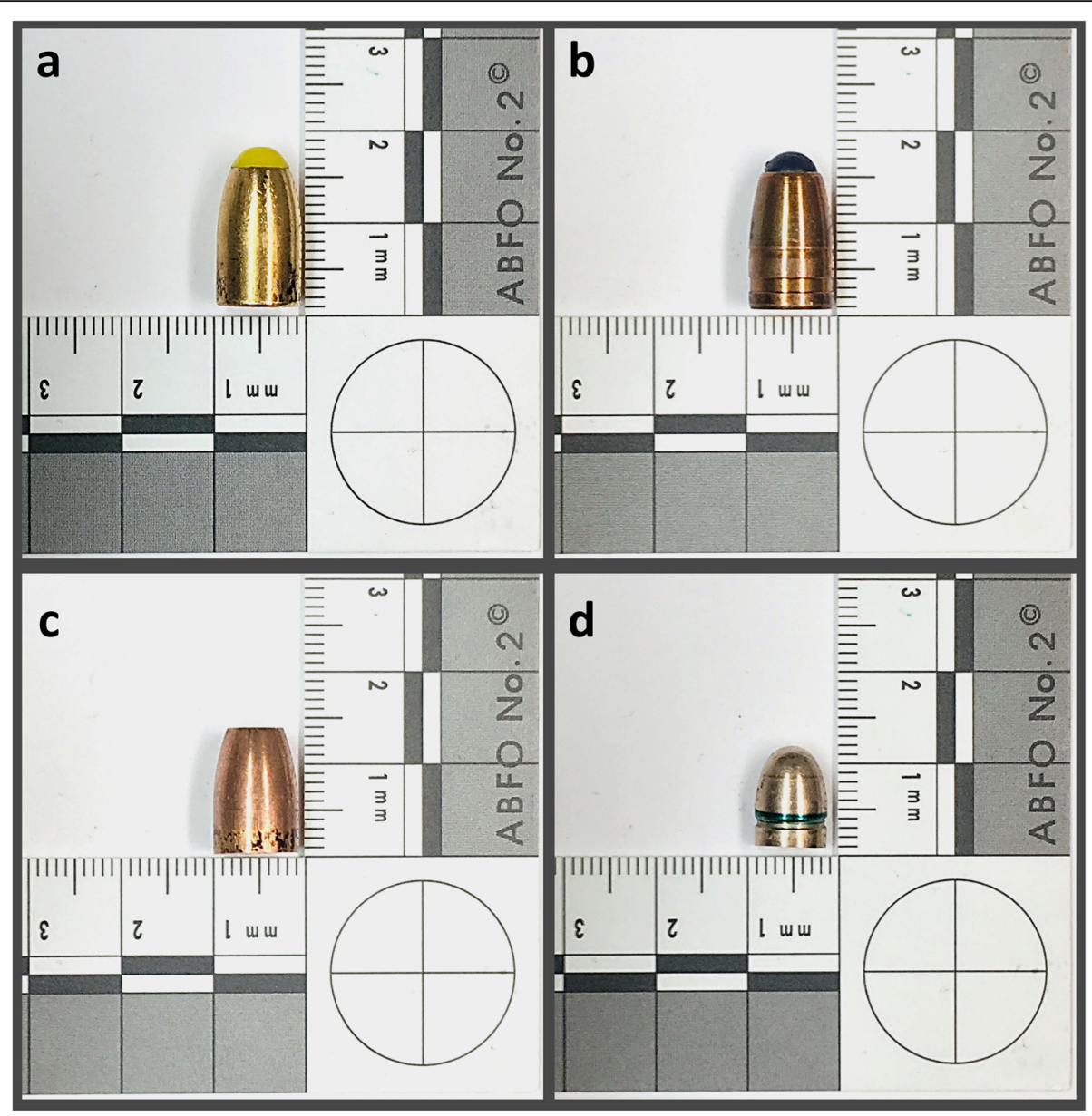

Fig. 1 Action 4 (a), QD-PEP (b), Hydra-Shok (c), and 7.65 Browning (d) bullets were fired into animal cadaver models at a dedicated shooting range. Then, computed tomography scans of the animal cadaver models with lodged copper bullets $(\mathbf{a}, \mathbf{b})$ and lodged lead bullets (c, $\mathbf{d})$ were performed

provides equivalent image noise. A standard pitch of 0.6 was used. The raw data were reconstructed using standard filtered back projection with a hard kernel (B70), a slice thickness of $1.5 \mathrm{~mm}$, and a field of view of $140 \times$ $140 \mathrm{~mm}$ (reconstruction matrix, $512 \times 512$; in-plane voxel size, $0.27 \times 0.27 \mathrm{~mm})$. Reconstructions were calculated in an extended CT scale (ECTS) to allow measurements beyond the standard range of HU values [22].

ROI measurements, CT numbers, and the dual-energy index CT numbers were measured in a defined ROI at 80,100 , 120 , and $140 \mathrm{kVp}$ (Fig. 2). To assure identical ROI placement, the datasets were displayed side by side in a multiplanar reconstruction view using dedicated software (MM Reading, syngo.via, Version VB10B HF03, Siemens Healthcare GmbH, Forchheim, Germany) [23]. The software enables the mean and maximum CT numbers to be measured within an ROI at the exact same position on all four datasets with different energy levels. ROI circles were drawn at the centre (ROI: $1.6 \mathrm{~mm}^{2}$ ) and edge (ROI: $0.5 \mathrm{~mm}^{2}$ ) of the lodged bullet. Measurements were taken separately at these two positions to demonstrate the influence of the bullet's caliber. For each bullet, six ROIs were positioned at different slices, i.e., different levels within the bullet or its fragments for the core and edge measurements (ROIs per bullet: core, $n=6$; edge, $n=6$ ). An ROI was repositioned on a new slice if the upper limit of $30,710 \mathrm{HU}$ was displayed as the maximum CT number. The DEI was calculated for dual-energy pairs of $80 / 100$ $\mathrm{kVp}, 80 / 120 \mathrm{kVp}, 80 / 140 \mathrm{kVp}, 100 / 120 \mathrm{kVp}, 100 / 140 \mathrm{kVp}$, and $120 / 140 \mathrm{kVp}$ using the mean CT numbers $\left(\mathrm{DEI}_{\text {mean }}\right)$ and the maximum $\mathrm{CT}$ numbers $\left(\mathrm{DEI}_{\max }\right)$ from the ROI measurements at the centre and edge of the lodged bullet. The following formula [24] was used to calculate the DEI:

$$
D E I=\frac{x_{\text {low }}-x_{\text {high }}}{x_{\text {low }}+x_{\text {high }}+2000}
$$

The variable $x_{\text {low }}$ represents the CT number measured at the lower energy level of the individual dual-energy pair, while $x_{\text {high }}$ is the CT number measured at the higher energy level. 


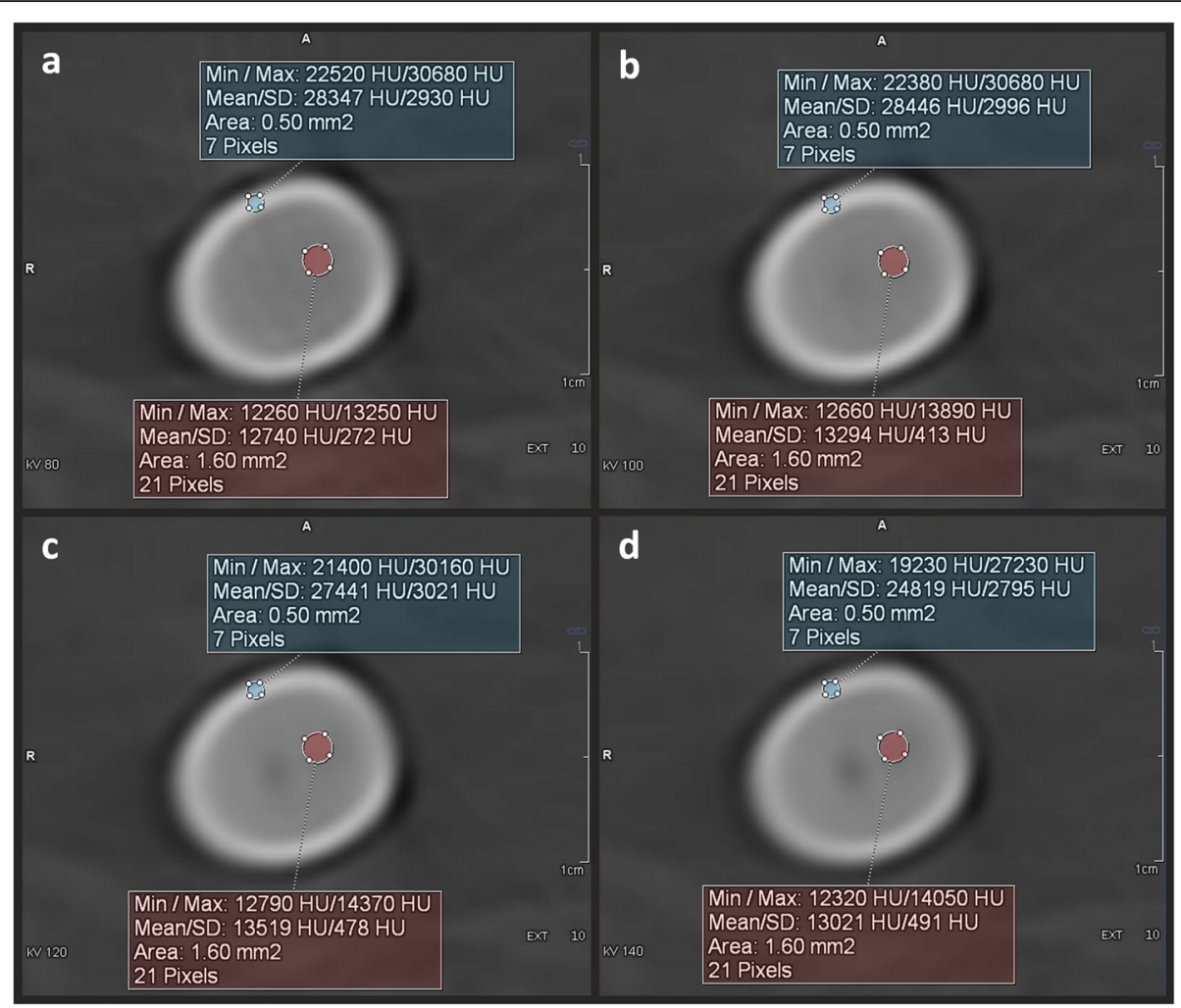

Fig. 2 Cross sections of a lodged Action 4 copper bullet at different energy levels indicated in kilo-voltage-peaks (kVp) (a, 80 kVp; b, 100 kVp; c, $120 \mathrm{kVp} ; \mathbf{d}, 140 \mathrm{kVp}$ ). Region-of-interest-based measurements were carried out in the hyperdense ring at the edge (area $0.5 \mathrm{~mm}^{2}$, highlighted in blue) and in the centre of the bullet (area $1.6 \mathrm{~mm}^{2}$, highlighted in red). Each pixel (i.e., voxel) contains a single CT number. The measurements indicate the mean computed tomography (CT) number, the standard deviation (SD), the minimum $C T$ number, and the maximum $C T$ number of all pixels within the ROI. The CT numbers (i.e., the x-ray attenuation values) are influenced by the energy level. CT numbers obtained from two different energy levels can be used to calculate the dual-energy index (DEI), which represents the ratio of the CT numbers of the two energy levels

\section{Distinction between copper and lead bullets}

The difference between using CT numbers from a single energy and the DEI for the distinction between copper and lead bullets within the animal cadaver models was assessed by considering the energy level, the use of the mean and maximum CT numbers, and the ROI position (core or edge). The two groups of bullets were compared using statistical analysis, standard deviations, and data overlap. Finally, the most suitable method with the lowest standard deviations and the smallest data overlap was applied and assessed in real forensic cases.

\section{Statistical analysis and data overlap calculations}

The overall mean values of the mean CT numbers, of the maximum CT numbers, and of the DEIs of each bullet were used for statistical analysis. The Shapiro-Wilk test was used to determine whether the data were normally distributed. The $t$ test was used for normally distributed data, and the Mann-Whitney $U$ test was used for non-normally distributed data to reveal statistically significant differences between the two groups of bullets (significance level, $p<0.05$ ). The statistical analyses were performed using the Statistical Package for the Social Sciences (SPSS, International Business Machines Corporation, IBM, Armonk, NY, USA).

\section{Results}

\section{Animal cadaver study}

All bullets were deformed, and the lead bullets were partially fragmented. If a bullet was fragmented, ROI measurements were conducted on the largest main fragment. One of the lead bullets was separated from its jacket, which was composed of a copper-zinc alloy (Fig. 3). This particular jacket was used to further examine the final method applied on real forensic cases in this study.

\section{Differences in $\mathrm{CT}$ numbers from single energies}

The mean and maximum CT numbers of a total of 576 ROI measurements are illustrated in Fig. 4. Table 1 lists 


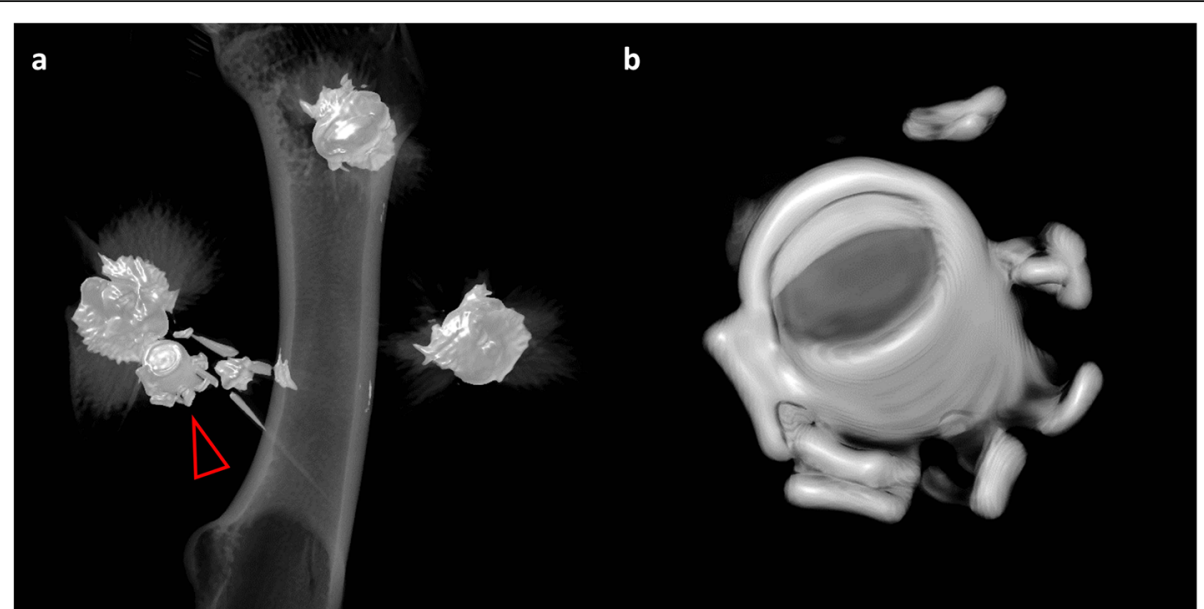

Fig. 3 Volume rendering of the Hydra-Shok bullets within the animal cadaver model obtained from the computed tomography scan with 140 $\mathrm{kVp}(\mathbf{a})$. The copper/zinc jacket (a, arrowhead; $\mathbf{b}$ ) of one of the Hydra-Shok bullets (Hydra-Shok number 2) was separated from the lead core of the bullet (a, arrowhead). All Hydra-Shok bullets were heavily deformed; however, they did not hit the femoral bone as no osseous fractures were detected. Metal artifacts are visible as streaks in the panel $\mathbf{a}$, but these streaks disappeared when a window that could precisely visualise the metallic object was selected (b)

the overall mean values and standard deviations, minimum and maximum values, and the statistical analysis of the mean and maximum CT numbers for the two groups at all four energy levels from the ROI measurements at the core and the edge of the lodged bullets.

At all four energy levels, the mean values of the (mean and maximum) CT numbers obtained from core measurements were higher in the copper group than in the lead group, while the mean values from the edge measurements exhibited the opposite relationship (i.e., the (mean and maximum) CT numbers obtained from core measurements were higher in the lead group than in the copper group). The standard deviations decreased with an increase in the energy level in the copper group; the same phenomenon occurred for the edge measurements in the lead group, while in the lead core, the standard deviations increased with an increase in the energy level. Furthermore, the (mean and maximum) CT
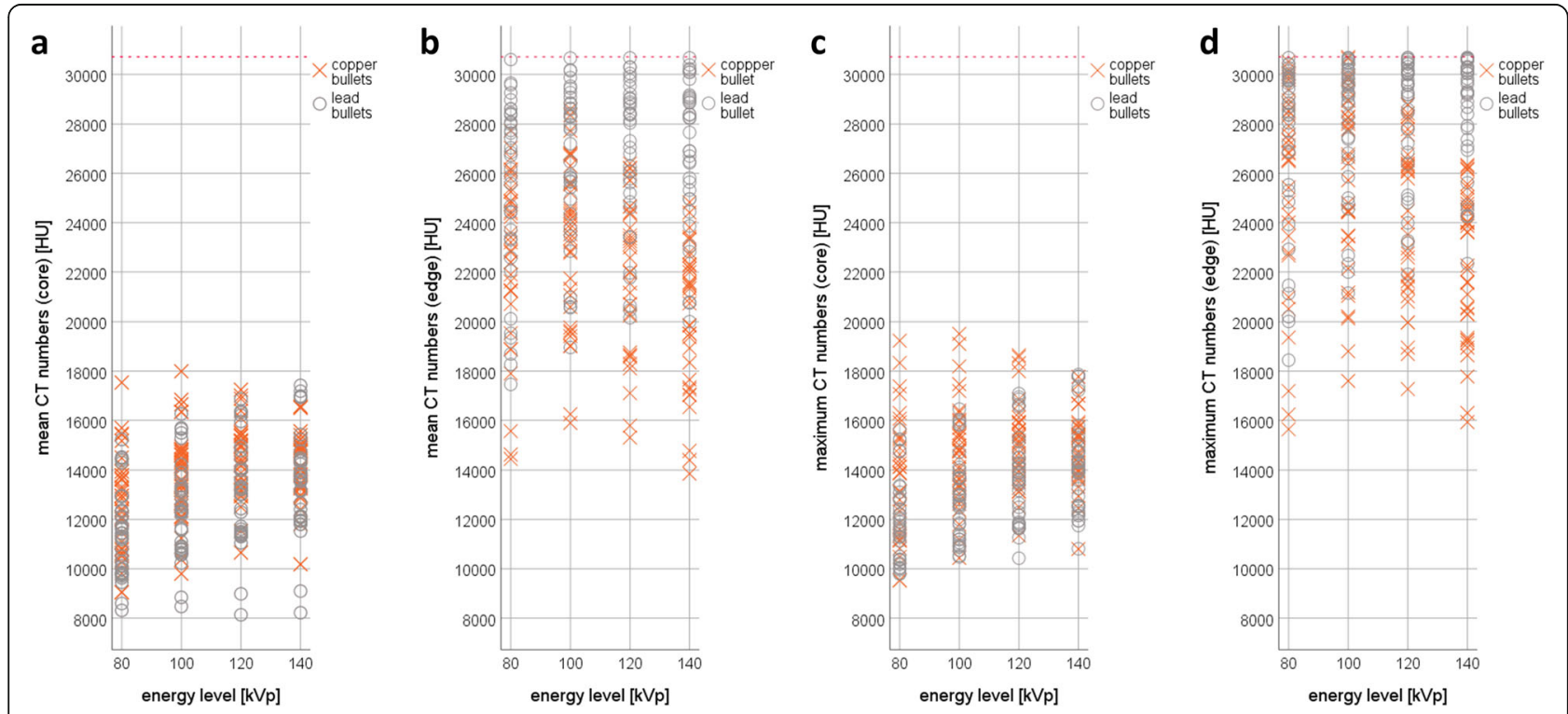

Fig. 4 Mean computed tomography (CT) numbers obtained from the cores (a) and the edges (b) of the bullets and the maximum CT numbers obtained from the cores (c) and the edges (d) of the bullets. The CT numbers of these two types of bullets demonstrate a strong overlap. The CT numbers from the cores were much lower than those from the edges. The red dashed line indicates the upper limit of the extended CT scale (ECTS) 
Table 1 CT numbers of copper and lead bullets

\begin{tabular}{|c|c|c|c|c|c|c|c|c|c|c|}
\hline \multicolumn{3}{|c|}{ Measurements } & \multicolumn{2}{|c|}{ Mean \pm standard deviation } & Min & Max & Min & Max & \multirow{2}{*}{$\begin{array}{l}\text { SW test } \\
p \text { value }\end{array}$} & \multirow{2}{*}{$\begin{array}{l}t \text { test } \\
p \text { value }\end{array}$} \\
\hline \multirow{2}{*}{$\begin{array}{l}\text { CT number } \\
\text { Mean }\end{array}$} & \multirow{2}{*}{$\begin{array}{l}\text { ROI position } \\
\text { Core }\end{array}$} & \multirow{2}{*}{$\begin{array}{r}\text { Energy }(\mathrm{kVp}) \\
80\end{array}$} & \multirow{2}{*}{$\begin{array}{l}\text { Copper bullets } \\
12,584 \pm 1,951\end{array}$} & \multirow{2}{*}{$\frac{\text { Lead bullets }}{11,406 \pm 1,724}$} & \multicolumn{2}{|c|}{ Copper bullets } & \multicolumn{2}{|c|}{ Lead bullets } & & \\
\hline & & & & & 9,041 & 17,535 & 8,312 & 15,227 & 0.448 & 0.836 \\
\hline & & 100 & $13,862 \pm 1,729$ & $12,315 \pm 1,867$ & 9,798 & 17,988 & 8,469 & 16,266 & 0.403 & 0.399 \\
\hline & & 120 & $14,462 \pm 1,435$ & $12,996 \pm 1,959$ & 10,654 & 17,243 & 8,133 & 16,869 & 0.610 & 0.155 \\
\hline & & 140 & $14,197 \pm 1,300$ & $13,514 \pm 2,048$ & 10,180 & 16,571 & 8,217 & 17,419 & 0.948 & 0.169 \\
\hline \multirow[t]{4}{*}{ Max } & Core & 80 & $13,649 \pm 2,368$ & $11,945 \pm 1,645$ & 9,520 & 19,230 & 9,790 & 15,630 & 0.457 & 0.714 \\
\hline & & 100 & $14,734 \pm 2,004$ & $12,848 \pm 1,692$ & 10,440 & 19,510 & 10,480 & 16,460 & 0.609 & 0.629 \\
\hline & & 120 & $15,186 \pm 1,639$ & $13,586 \pm 1,754$ & 11,350 & 18,640 & 10,430 & 17,090 & 0.463 & 0.347 \\
\hline & & 140 & $14,820 \pm 1,389$ & $14,054 \pm 1,838$ & 10,800 & 17,770 & 10,810 & 17,860 & 0.397 & 0.275 \\
\hline \multirow[t]{4}{*}{ Mean } & Edge & 80 & $22,708 \pm 3,360$ & $25,488 \pm 3,617$ & 14,448 & 27,730 & 17,461 & 30,598 & 0.991 & 0.423 \\
\hline & & 100 & $23,295 \pm 3,212$ & $26,412 \pm 3,136$ & 15,897 & 28,579 & 18,956 & 30,660 & 0.975 & 0.888 \\
\hline & & 120 & $21,976 \pm 3,036$ & $26,751 \pm 2,995$ & 15,304 & 26,394 & 20,160 & 30,668 & 0.896 & 0.727 \\
\hline & & 140 & $20,272 \pm 2,840$ & $26,976 \pm 2,880$ & 13,854 & 24,828 & 20,000 & 30,665 & 0.460 & 0.532 \\
\hline \multirow[t]{4}{*}{ Max } & Edge & 80 & $25,854 \pm 4,045$ & $27,251 \pm 3,395$ & 15,640 & 30,510 & 18,440 & 30,670 & 0.364 & 0.421 \\
\hline & & 100 & $25,934 \pm 3,582$ & $28,068 \pm 2,731$ & 17,600 & 30,700 & 21,160 & 30,680 & 0.734 & 0.733 \\
\hline & & 120 & $24,277 \pm 3,248$ & $28,340 \pm 2,478$ & 17,270 & 28,780 & 21,910 & 30,680 & 0.448 & 0.818 \\
\hline & & 140 & $22,290 \pm 2,926$ & $28,628 \pm 2,226$ & 15,930 & 26,340 & 22,340 & 30,680 & 0.168 & 0.655 \\
\hline
\end{tabular}

Min Minimum value, Max Maximum value, $R O I$ Region of interest; $S W$ test Shapiro-Wilk test

numbers obtained from lead bullets increased with an increase in the energy level from 80 to $140 \mathrm{kVp}$. However, the CT numbers measured in the copper bullets presented an increase only from 80 to $120 \mathrm{kVp}$ in the core and from 80 to $100 \mathrm{kVp}$ at the edge. A peak occurred for the $\mathrm{CT}$ numbers at $120 \mathrm{kVp}$ (core) and at $100 \mathrm{kVp}$ (edge), and the CT numbers decreased at higher energy levels. The Shapiro-Wilk test indicated that the mean and maximum $\mathrm{CT}$ numbers were normally distributed; therefore, the $t$ test was applied. The $t$ tests revealed no statistically significant differences between the CT numbers of copper and lead bullets.

\section{Differences in the dual-energy index}

Table 2 lists the overall mean values and standard deviations or median values and interquartile ranges, minimum and maximum values, and the statistical analysis of the DEIs of each group calculated from core-based and edge-based CT numbers for all six dual-energy pairs. The copper group demonstrated higher DEIs than the lead group except for the 80/100 and 80/120 DEImean values and the $80 / 100 \mathrm{DEI}_{\max }$ value based on core measurements. In the core, statistically significant differences between copper and lead bullets were detected for the $80 / 100$ and $80 / 120 \mathrm{DEI}_{\max }$ values (each, $p=0.002$ ). Concerning edge measurements, a statistically significant difference was detected for the 100/120 DEI mean value and $100 / 120,100 / 140$, and $120 / 140 \mathrm{DEI}_{\max }$ values (each, $p=0.002$ ). The DEIs of the lead bullets that differed significantly from the copper bullets presented small standard deviations (range, \pm 0.008 to \pm 0.014 ) or interquartile ranges (range, 0.005-0.015), while those of the copper bullets presented larger standard deviations (range, \pm 0.023 to \pm 0.036 ) or interquartile ranges (range, 0.024-0.028) except for the 120/140 DEI $\mathrm{I}_{\max }$. The edgebased 120/140 $\mathrm{DEI}_{\max }$ presented small interquartile ranges in both groups of bullets (copper bullets, 0.011; lead bullets, 0.005) and a gap between the calculated DEIs of the two groups (Fig. 5); therefore, the edgebased 120/140 DEI $\mathrm{max}_{\max }$ was deemed the most appropriate for distinguishing between copper and lead bullets. A boundary at 0.004 was identified between the two groups.

The 120/140 DEI $\mathrm{Dax}_{\max }$ was also calculated for the jacket composed of copper (and zinc) that was separated from the lead core after entering the animal cadaver (Fig. 3). The jacket yielded a 120/140 DEI $\mathrm{max}_{\max }$ above the threshold (mean value, 0.064; range, 0.051-0.072), which was also observed for all solid copper bullets. Consequently, the separated jacket clearly differed from its initial lead core and from all (still) jacketed lead bullets in the 120/140 DEI $_{\max }$. Interestingly, the Hydra-Shok no. 2 bullet, the "unjacketed" lead bullet, presented lower DEIs than the other lead bullets (Fig. 5).

\section{Real forensic cases}

Similar to the animal cadavers, all three Action 4 copper bullets lodged in decedents were deformed, while all three unjacketed $.22 L R$ lead bullets were deformed and partially fragmented. The bullets were located in the 
Table 2 Dual-energy indexes for copper and lead bullets

\begin{tabular}{|c|c|c|c|c|c|c|c|c|c|c|}
\hline \multicolumn{3}{|c|}{ Measurements } & \multicolumn{2}{|c|}{$\begin{array}{l}\text { Mean } \pm \text { standard deviation or } \\
\text { median (interquartile range) }\end{array}$} & \multirow{2}{*}{\multicolumn{2}{|c|}{$\begin{array}{l}\text { Min Max } \\
\text { Copper bullets }\end{array}$}} & \multirow{2}{*}{\multicolumn{2}{|c|}{$\begin{array}{l}\text { Min Max } \\
\text { Lead bullets }\end{array}$}} & \multirow{2}{*}{$\begin{array}{l}\text { SW test } \\
p \text { value }\end{array}$} & \multirow{2}{*}{$\begin{array}{l}t \text { test or MW } U \text { test } \\
p \text { value }\end{array}$} \\
\hline CT number & ROI position & Dual energy $(\mathrm{k} \vee \mathrm{p} / \mathrm{k} \vee \mathrm{p})$ & Copper bullets & Lead bullets & & & & & & \\
\hline \multirow[t]{6}{*}{ Mean } & Core & $80 / 100$ & $-0.047 \pm 0.020$ & $-0.035 \pm 0.009$ & -0.091 & -0.011 & -0.051 & -0.008 & 0.514 & 0.090 \\
\hline & & $80 / 120$ & $-0.068 \pm 0.031$ & $-0.060 \pm 0.016$ & -0.140 & 0.014 & -0.081 & 0.010 & 0.351 & 0.070 \\
\hline & & $80 / 140$ & $-0.059 \pm 0.039$ & $-0.078 \pm 0.020$ & -0.132 & 0.056 & -0.103 & 0.005 & 0.693 & 0.080 \\
\hline & & $100 / 120$ & $-0.021 \pm 0.015$ & $-0.025 \pm 0.009$ & -0.050 & 0.027 & -0.039 & 0.018 & 0.858 & 0.259 \\
\hline & & $100 / 140$ & $-0.013 \pm 0.024$ & $-0.043 \pm 0.013$ & -0.059 & 0.068 & -0.056 & 0.013 & 0.516 & 0.323 \\
\hline & & $120 / 140$ & $0.008 \pm 0.011$ & $-0.018 \pm 0.006$ & -0.011 & 0.042 & -0.029 & -0.005 & 0.104 & 0.264 \\
\hline \multirow[t]{6}{*}{ Max } & Core & $80 / 100$ & $-0.038 \pm 0.023$ & $-0.034 \pm 0.008$ & -0.099 & 0.004 & -0.049 & -0.019 & 0.405 & $0.014^{*}$ \\
\hline & & $80 / 120$ & $-0.054 \pm 0.036$ & $-0.060 \pm 0.014$ & -0.139 & 0.017 & -0.079 & -0.016 & 0.880 & $0.016^{*}$ \\
\hline & & $80 / 140$ & $-0.042(0.074)$ & $-0.076(0.015)$ & -0.122 & 0.068 & -0.098 & -0.021 & $0.014^{*}$ & 0.065 \\
\hline & & $100 / 120$ & $-0.016 \pm 0.018$ & $-0.026 \pm 0.011$ & -0.051 & 0.023 & -0.048 & 0.007 & 0.731 & 0.612 \\
\hline & & $100 / 140$ & $-0.005 \pm 0.027$ & $-0.042 \pm 0.011$ & -0.050 & 0.075 & -0.055 & 0.002 & 0.233 & 0.272 \\
\hline & & $120 / 140$ & $0.011 \pm 0.013$ & $-0.016 \pm 0.009$ & -0.013 & 0.051 & -0.034 & 0.003 & 0.154 & 0.521 \\
\hline \multirow[t]{6}{*}{ Mean } & Edge & $80 / 100$ & $-0.013 \pm 0.031$ & $-0.019 \pm 0.022$ & -0.129 & 0.052 & -0.082 & 0.047 & 0.150 & 0.829 \\
\hline & & $80 / 120$ & $0.015 \pm 0.046$ & $-0.025 \pm 0.024$ & -0.158 & 0.111 & -0.109 & 0.027 & 0.228 & 0.278 \\
\hline & & $80 / 140$ & $0.053 \pm 0.050$ & $-0.030 \pm 0.031$ & -0.141 & 0.178 & -0.131 & 0.016 & 0.481 & 0.675 \\
\hline & & $100 / 120$ & $0.028(0.028)$ & $-0.005(0.008)$ & -0.029 & 0.065 & -0.029 & 0.003 & $0.037^{*}$ & $0.002^{*}$ \\
\hline & & $100 / 140$ & $0.066 \pm 0.025$ & $-0.011 \pm 0.014$ & -0.012 & 0.134 & -0.050 & 0.017 & 0.114 & 0.232 \\
\hline & & $120 / 140$ & $0.039 \pm 0.011$ & $-0.004 \pm 0.010$ & 0.012 & 0.069 & -0.037 & 0.025 & 0.062 & 0.418 \\
\hline \multirow[t]{6}{*}{ Max } & Edge & $80 / 100$ & $-0.004(0.034)$ & $-0.007(0.016)$ & -0.103 & 0.063 & -0.084 & 0.000 & $0.027^{*}$ & 0.065 \\
\hline & & $80 / 120$ & $0.028 \pm 0.045$ & $-0.021 \pm 0.024$ & -0.131 & 0.094 & -0.111 & 0.000 & 0.623 & 0.649 \\
\hline & & $80 / 140$ & $0.069 \pm 0.050$ & $-0.026 \pm 0.031$ & -0.124 & 0.158 & -0.136 & 0.000 & 0.276 & 0.952 \\
\hline & & $100 / 120$ & $0.032(0.024)$ & $-0.002(0.007)$ & -0.028 & 0.073 & -0.027 & 0.003 & $0.039^{*}$ & $0.002^{*}$ \\
\hline & & $100 / 140$ & $0.080(0.028)$ & $-0.006(0.015)$ & -0.021 & 0.121 & -0.052 & 0.002 & $0.017^{*}$ & $0.002^{*}$ \\
\hline & & $120 / 140$ & $0.040(0.011)$ & $-0.002(0.005)$ & 0.007 & 0.065 & -0.044 & 0.002 & $0.012^{*}$ & $0.002^{*}$ \\
\hline
\end{tabular}

Min Minimum value, Max Maximum value, ROI Region of interest; SW test Shapiro-Wilk test; MW U test Mann-Whitney $U$ test

*Statistically significant values

cranium (cases 1, 2, and 4), the dorsal muscles (cases 3 and 6), and the muscles of the upper arm (case 5). The lead bullets fragmented into several pieces and tiny metal fragments were scattered along the wound channel. The fragments did not allow visual classification or caliber measurements (Fig. 6). According to the results of the animal cadaver study, the edge-based 120/140 $\mathrm{DEI}_{\max }$ was applied for the decedents. Since the CT numbers at $120 \mathrm{kVp}$ and $140 \mathrm{kVp}$ had to be measured for calculation of the DEI, these CT numbers were also compared between the individual cases. At both energy levels, only two of the three Action 4 copper bullets (cases 2 and 5) presented lower CT numbers than the $.22 \mathrm{LR}$ lead bullets in all other cases, while the Action 4 copper bullet in case 6 was not distinguishable from the lead bullets using the CT numbers (Fig. 7a and b). However, the $120 / 140 \mathrm{DEI}_{\max }$ allowed a clear distinction between copper and lead bullets (Fig. 7c). All lead bullets presented DEI values below the threshold of 0.004, while all copper bullets had DEI values far above this threshold. The Action 4 bullet in case 6, which did not differ from lead bullets according to its CT numbers, was located approximately $12 \mathrm{~cm}$ from the 10th thoracic vertebra. A closer look at this particular copper bullet revealed that beam hardening was very unevenly distributed along the hyperdense ring at the edge of the bullet (Fig. 8).

\section{Discussion}

This study highlights some important factors that must be considered for the differentiation between copper and lead bullets according to their metallic components using CT. At $80,100,120$, and $140 \mathrm{kVp}$, the CT numbers of copper bullets did not significantly differ from those of lead bullets, and using CT numbers alone can lead to false classifications. The ratio between CT numbers at two different energy levels indicated by the DEI 

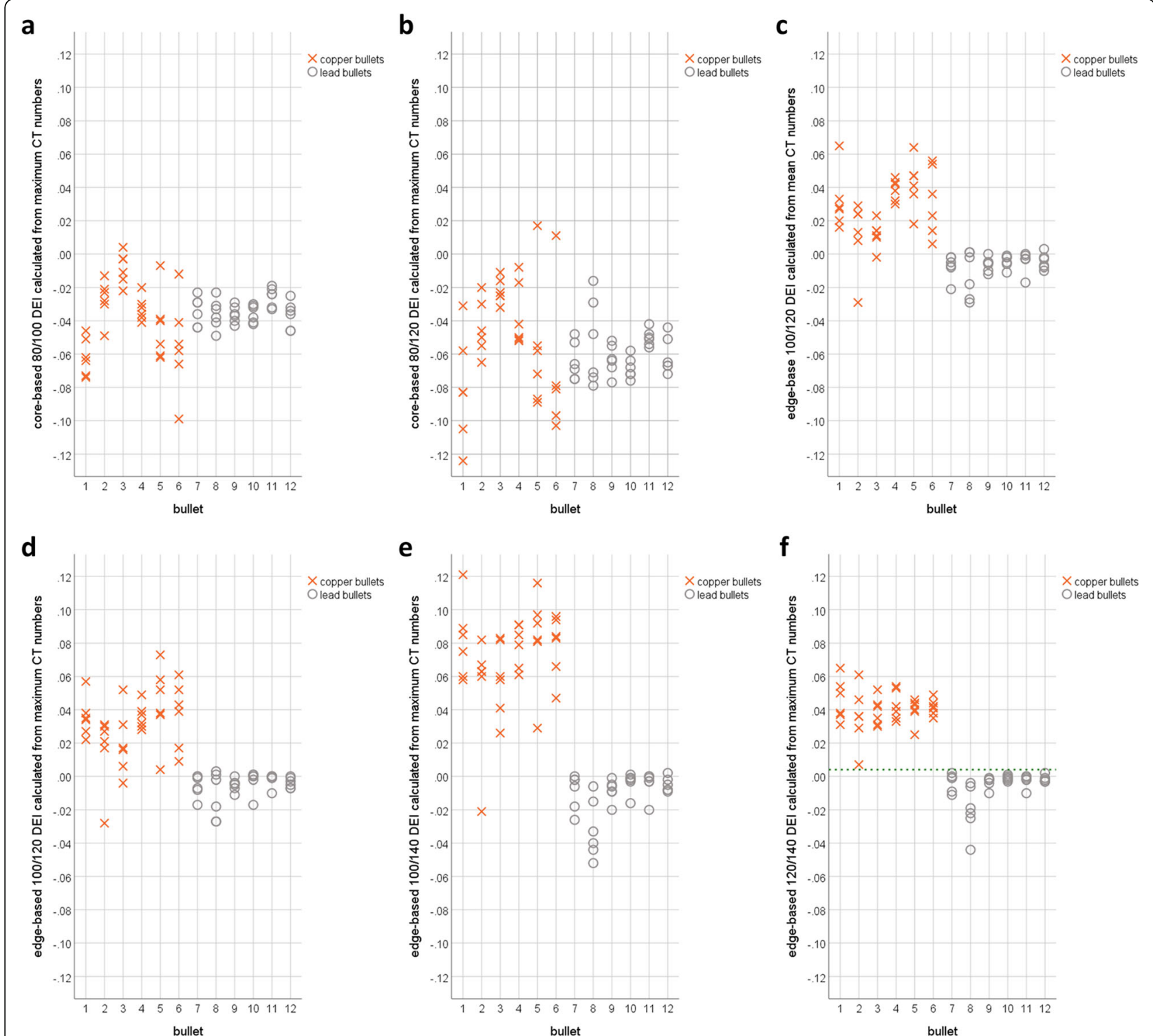

Fig. 5 The core-based 80/100 dual-energy index (DEI) $\max (\mathbf{a})$, the core-based 80/120 DEI $I_{\max }(\mathbf{b})$, the edge-based 100/120 DEI mean $(\mathbf{c})$, the edgebased 100/120 DEI $I_{\max }(\mathbf{d})$, the edge-based 120/140 DEI $\max (\mathbf{e})$, and the edge-based 120/140 DEI max (f) yielded statistically significant differences between the two groups of bullets (x-axis: Action 4 bullets, 1-3; QD-PEP bullets, 4-6; Hydra-Shok bullets, 7-9; 7.65 Browning bullets, 10-12). While large overlaps are visible for core measurements, the copper group visibly differed from the lead group in terms of the DEl calculated from edge measurements. Only the edge-based 120/140 DEI max resulted in a clear dividing line between the two groups of bullets (green dashed line). The Hydra-Shok no. 2 (bullet number 8 on the $x$-axis), which was separated from its jacket, yielded lower values than all other copper/zinc-jacketed lead bullets.

is more suitable to distinguish copper from lead bullets. For this ratio, the maximum CT numbers appeared to be more appropriate than the mean CT numbers. In the core, only the CT number ratios between low energies $\left(80 / 100\right.$ and $\left.80 / 120 \mathrm{DEI}_{\max }\right)$ presented significant differences but these CT number ratios presented also large data overlaps and large standard deviations for the copper bullets. In contrast, in the edge, only the CT number ratios between high energies presented significant differences $\left(100 / 120,100 / 140\right.$, and $\left.120 / 140 \mathrm{DEI}_{\max }\right)$. Only the
$120 / 140 \mathrm{DEI}_{\max }$ obtained from edge measurements exhibited small standard deviations for both groups of bullets and a gap between the data of both groups. The edge-based 120/140 DEI $\mathrm{Dmax}_{\max }$ was successfully introduced into postmortem imaging of deceased gunshot victims.

Beam hardening occurs at the edge of a bullet or its fragment $[18,25]$; thus, the measured CT numbers are not "real". However, while this physical effect barely affects the DEI, it considerably affects the CT number, as demonstrated in case 6 of the real forensic cases, where 


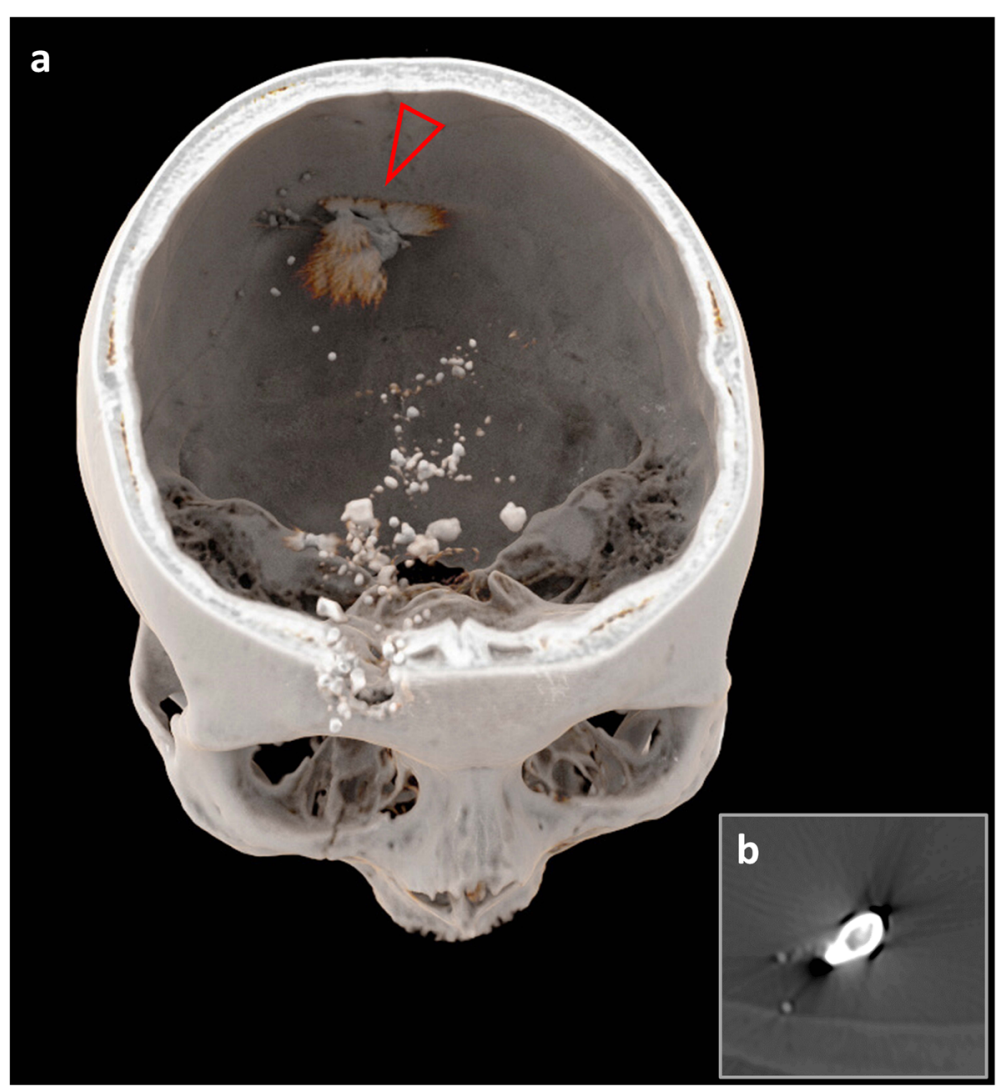

Fig. 6 Cinematic rendering of a cerebral non-perforating gunshot wound (case 1) obtained from a computed tomography (CT) examination of the decedent's head at $120 \mathrm{kVp}$ (a). The entrance wound is located on the left side of the frontal bone. Numerous bone fragments and tiny metal fragments are scattered along the bullet path. The bullet fragment is lodged in the occipital lobe above the posterior cranial fossa (a, arrowhead). Visual identification of the bullet was not feasible via CT due to its severe deformation (b)

the CT numbers were unexpectedly high for a copper bullet. Nonetheless, the DEI calculated from those unexpectedly high CT numbers still allowed clear classification of the bullet due to the slight decrease in the maximum CT numbers from 120 to $140 \mathrm{kVp}$. An increase or a decrease in CT numbers over all four energy levels is related to the atomic numbers $(Z)$ and the $K$-edge energies of the individual metals (copper, $Z=29$; $K$-edge $=8.9 \mathrm{keV}$; lead, $Z=$ $82 ; K$-edge $=88.0 \mathrm{keV})$ and the photoelectric effect [18]. Differentiation between bullets composed of metallic components with atomic numbers that are close together in the periodic table might be considerably more challenging using the DEI-based approach.

Maximum CT numbers are usually not used since they are strongly affected by quantum and image noise. Therefore, using the same scanning and reconstruction parameters as well as the same volume CT dose index is important for repeated scans with two different energies. Complying with these conditions, the ratio between maximum CT numbers within the same ROI from two different energy levels can be a robust indicator for the attenuation characteristics of metallic objects.
Although the ROIs at the edge of the jacketed lead bullets very likely included some pixels/voxels located in the bullets' jackets, which are composed of copper-zinc alloy, the material of the jacket did not affect the identification of lead bullets. The DEIs of the jackets of lead bullets in the animal cadaver study did not noticeably differ from those of the unjacketed .22 LR bullets in the real forensic cases. Lead presents very high CT numbers; thus, the CT numbers of the less radiopaque metal in the jacket hardly affects the mean or maximum CT numbers obtained from ROI measurements. However, a jacket composed of copper-zinc alloy that is separated from the bullet, which occurred once in this study, can be differentiated from its unjacketed lead core or other jacketed lead bullets.

Core measurements are considered unreliable for differentiating between copper and lead bullets since large data overlaps were calculated and large standard deviations were observed for the copper bullets. Similar to CT numbers measured at the edge, CT numbers measured in the centre are not "real". Previous studies on material differentiation $[20,21,26]$ used the mean CT 

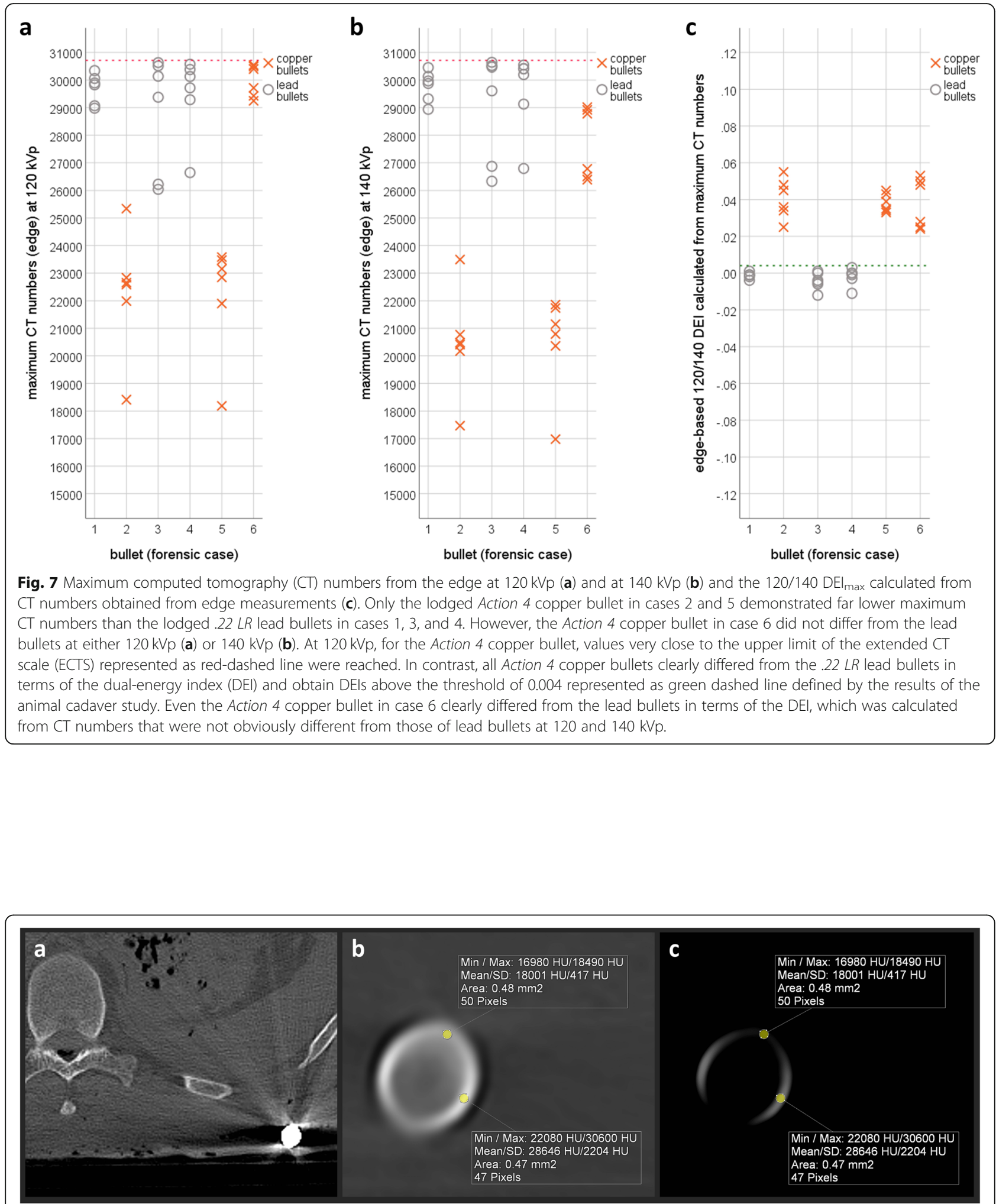

Fig. 8 The Action 4 copper bullet in case 6 was lodged in the dorsal muscles (a). The computed tomography numbers at $120 \mathrm{kVp}$ varied from those that are consistent with copper bullets (b, c: $18,490 \mathrm{HU})$ to those that are consistent with lead bullets (a, $\mathbf{b}: 30,600 \mathrm{HU})$. A high window centre can be used to illustrate unevenly distributed beam hardening along the hyperdense ring at the edge of the bullet (c). Since the beam hardening artifact is pronounced in the diagonal vertical direction of the x-ray beam, the vertebral bone and x-ray scattering may have affected the intensity of beam hardening at the edge of this particular bullet 
numbers from the centre of the objects to distinguish between metallic foreign bodies. The authors pointed out that CT numbers must be measured far from nearsurface regions to ensure reliable $\mathrm{HU}$ values and to avoid partial volume effects [20, 21, 26]. However, the CT number of a metallic object strongly decreases with the $\mathrm{x}$-ray penetration depth. This cupping effect, which increases with the diameter of a bullet, was shown for intact bullets in a previous ex situ study on intact bullets [25]. Additionally, photon starvation increases with the size of a radiopaque object, indicating that the detector receives noisier information regarding the $\mathrm{x}$-ray attenuation at the centre of the material. Consequently, the CT numbers obtained from a radiopaque material vary depending on the ROI position and the ROI size.

Some limitations of this study should be noted. First, only bullets composed of copper or lead were investigated. However, these are the most frequently encountered types of bullets $[27,28]$. Other metallic components, such as steel, bismuth, and tungsten, are much less often used for the bullet core, while steel is more frequently used for the jackets of bullets. To distinguish ferromagnetic steeljacketed bullets from non-ferromagnetic non-steel-jacketed bullets, different studies yielded contradictory results $[17,29]$ since the type of metal used for the core of the bullet (usually copper or lead) was not considered [18, 29]. Notably, some bullets have different core metals at the point than at the body. Second, only a small number of bullets were used in this study, consequently minimising the statistical power of the results. Additionally, the ROIs at the edges of the bullets contained only a small number of pixels (see Fig. 2). Despite the small number of bullets used in the animal cadaver study and the small number of pixels in the ROIs, the selected $120 / 140 \mathrm{DEI}_{\max }$ was successfully applied to decedents. Third, intra-observer agreement and interobserver agreement were not tested in this study. However, a previous study [26] reported negligible observer variabilities for ROI measurements. Fourth, interscanner variability was not assessed in this study. Fifth, a potential benefit of using the dual-energy technique could not be assessed since the dual-energy data do not allow ECTS reconstructions. Additionally, CT numbers above the upper limit of the ECTS had to be excluded in this study.

In conclusion, this study presents a viable approach for in situ distinction of bullets composed of different metallic components according to their $\mathrm{x}$-ray attenuation characteristics at two different energy levels. If the bullet geometry is not visually identifiable due to deformation or fragmentation, then in situ classification of bullets according to their metallic components can provide rapid information on the type of bullet. Since CT scanning is routinely performed on shooting victims in emergency hospitals [30, 31] and increasingly applied postmortem in forensic medicine [32-34], in situ distinction between copper and lead bullets is becoming increasingly feasible.

\section{Abbreviations}

$C T$ : Computed tomography; DEl: Dual-energy index; ECTS: Extended CT scale; $\mathrm{HU}$ : Hounsfield unit; ROI: Region of interest

\section{Acknowledgements}

We thank Stephan Christen from the Forensic Institute in Zurich and Patrick Kircher from the Vetsuisse Faculty (University of Zurich) for endorsing the collaboration in this field of research. In addition, we are grateful to Emma Louise Kessler for her donation to the Zurich Institute of Forensic Medicine, University of Zurich, Switzerland.

\section{Authors' contributions}

DG, NZ, and SS designed the study. HR provided the animal cadaver models. $A B$ performed the shooting experiments (on the animal cadaver models), and PW, DG, NZ, and HR helped with the shooting experiments. MJT provided the technical equipment. DG performed the measurements and wrote the original draft of the manuscript. All authors reviewed the final manuscript.

\section{Funding}

The authors state that this work has not received any funding.

\section{Ethics approval}

This study was performed with human cadavers. Ethical approval was waived by the responsible ethics committee of the Canton of Zurich (waiver number: 2015-0686). This article does not contain any studies with (living) human participants.

No animals were killed for the scientific purposes of this study. The animal models used in this study were obtained from an institute of veterinary pathology. Fresh cadavers were used as an addition to another study and are in accordance with the 3Rs (replacement, reduction, and

refinement) - the guiding principles for the ethical use of animals in science. Ethical approval was waived.

Consent for publication

Not applicable.

\section{Competing interests}

The authors declare that they have no competing interests to report.

\section{Author details}

${ }^{1}$ Department of Forensic Medicine and Imaging, Institute of Forensic Medicine, University of Zurich, Winterthurerstrasse 190/52, CH-8057 Zurich, Switzerland. ${ }^{2}$ Department of Psychiatry, Psychotherapy and Psychosomatics, Hospital of Psychiatry, University of Zurich, Zurich, Switzerland. ${ }^{3}$ Diagnostic Imaging Research Unit (DIRU), Clinic for Diagnostic Imaging, Vetsuisse Faculty, University of Zurich, Zurich, Switzerland. ${ }^{4}$ Zurich Forensic Science Institute, Zurich Canton Police and Zurich City Police, Zurich, Switzerland. ${ }^{5}$ Institute of Forensic Medicine, Health Department Basel, University of Basel, Basel, Switzerland.

Received: 12 March 2020 Accepted: 15 June 2020

Published online: 06 July 2020

\section{References}

1. Stein KM, Bahner ML, Merkel J, Ain S, Mattern R (2000) Detection of gunshot residues in routine CTs. Int J Legal Med 114:15-18. https://doi.org/10.1007/ s004149900124

2. Gascho D, Marosi M, Thali MJ, Deininger-Czermak E (2020) Postmortem computed tomography and magnetic resonance imaging of gunshot wounds to the neck. J Forensic Sci. https://doi.org/10.1111/1556-4029.14311

3. Lantz PE, Jerome WG, Jaworski JA (1994) Radiopaque deposits surrounding a contact small-caliber gunshot wound. Am J Forensic Med Pathol 15:1013. https://doi.org/10.1097/00000433-199403000-00003 
4. Karger B, Hoekstra A, Schmidt PF (2001) Trajectory reconstruction from trace evidence on spent bullets. I. Deposits from intermediate targets. Int J Legal Med 115:16-22. https://doi.org/10.1007/s004140000202

5. Wunnapuk K, Minami T, Durongkadech P et al (2009) Discrimination of bullet types using analysis of lead isotopes deposited in gunshot entry wounds. Biol Trace Elem Res 129:278-289. https://doi.org/10.1007/s12011008-8304-7

6. DiMaio VJMD (1999) Gunshot wounds: practical aspects of firearms, ballistics, and forensic techniques. CRC-Press, New York

7. Marais AAS, Dicks HJ (2019) Utilization of x-ray computed tomography for the exclusion of a specific calibre and bullet type in a living shooting victim. J Forensic Sci 64:264-269. https://doi.org/10.1111/1556-4029.13805

8. Alves AM, Picoli FF, Silveira RJ et al (2020) When forensic radiology meets ballistics-in vivo bullet profiling with computed tomography and autopsy validation: a case report. Forensic Imaging. https://doi.org/10.1016/j.fri.2020. 200357

9. Dhillon MS, Dhatt SS (2012) First aid and emergency management in orthopedic injuries. JP Medical Ltd, New Delhi

10. Makhlouf F, Scolan V, Ferretti G, Stahl C, Paysant F (2013) Gunshot fatalities: correlation between post-mortem multi-slice computed tomography and autopsy findings: a 30-months retrospective study. Leg Med (Tokyo) 15:145148. https://doi.org/10.1016/j.legalmed.2012.11.002

11. Kirchhoff SM, Scaparra EF, Grimm J et al (2016) Postmortem computed tomography (PMCT) and autopsy in deadly gunshot wounds-a comparative study. Int J Legal Med 130:819-826. https://doi.org/10.1007/ s00414-015-1225-z

12. Gascho D, Zoelch N, Deininger-Czermak E et al (2020) Visualization and material-based differentiation of lodged projectiles by extended CT scale and the dual-energy index. J Forensic Lega Med. https://doi.org/10.1016/j. jflm.2020.101919

13. Padrta JC, Barone JE, Reed DM, Wheeler G (1997) Expanding handgun bullets. J Trauma 43:516-520. https://doi.org/10.1097/00005373-19970900000022

14. Haag LC (2013) The forensic aspects of contemporary disintegrating rifle bullets. Am J Forensic Med Pathol 34:50-55. https://doi.org/10.1097/PAF. Ob013e31827a05b7

15. Kaplan J, Klose R, Fossum R, Di Maio VJM (1998) Centerfire frangible ammunition: wounding potential and other forensic concerns. Am J Forensic Med Pathol 19:299-302. https://doi.org/10.1097/00000433199812000-00001

16. Coupland R (1999) Clinical and legal significance of fragmentation of bullets in relation to size of wounds: retrospective analysis. BMJ 319:403-406. https://doi.org/10.1136/bmj.319.7207.403

17. Diallo I, Auffret M, Deloire L, Saccardy C, Aho S, Ben Salem D (2018) Is dualenergy computed tomography helpful to determinate the ferromagnetic property of bullets? J Forensic Radiol Imaging 15:21-25. https://doi.org/10. 1016/j.jofri.2018.10.001

18. Gascho D, Zoelch N, Richter H, Buehlmann A, Wyss P, Schaerli S (2019) Identification of bullets based on their metallic components and $\mathrm{x}$-ray attenuation characteristics at different energy levels on CT. AJR Am J Roentgenol 213:W105-W113. https://doi.org/10.2214/AJR.19.21229

19. Ognard J, Dissaux B, Diallo I, Attar L, Saccardy C, Ben Salem D (2019) Manual and fully automated segmentation to determine the ferromagnetic status of bullets using computed tomography dual-energy index: a phantom study. J Comput Assist Tomogr 43:799-804. https://doi.org/10.1097/RCT. 0000000000000899

20. Bolliger SA, Oesterhelweg L, Spendlove D, Ross S, Thali MJ (2009) Is differentiation of frequently encountered foreign bodies in corpses possible by Hounsfield density measurement? J Forensic Sci 54:1119-1122. https://doi.org/10.1111/j.1556-4029.2009.01100.x

21. Ruder TD, Thali Y, Bolliger SA et al (2012) Material differentiation in forensic radiology with single-source dual-energy computed tomography. Forensic Sci Med Pathol 9:163-169. https://doi.org/10.1007/s12024-012-9398-y

22. Gascho D, Thali MJ, Niemann T (2018) Post-mortem computed tomography: technical principles and recommended parameter settings for highresolution imaging. Med Sci Law 58:70-82. https://doi.org/10.1177/ 0025802417747167

23. Gascho D, Philipp H, Flach PM, Thali MJ, Kottner S (2018) Standardized medical image registration for radiological identification of decedents based on paranasal sinuses. J Forensic Lega Med 54:96-101. https://doi.org/ 10.1016/j.jflm.2017.12.003
24. Krauss B, Schmidt B, Flohr TG (2011) Dual source CT. In: Johnson T, Fink C, Schönberg SO, Reiser MF (eds) Dual energy CT in clinical practice. Springer, Berlin, Heidelberg. https://doi.org/10.1007/174_2010_44

25. Paulis LE, Kroll J, Heijnens L et al (2019) Is CT bulletproof? On the use of CT for characterization of bullets in forensic radiology. Int J Legal Med. https://doi.org/10.1007/s00414-019-02033-0

26. Ruder TD, Thali Y, Schindera ST et al (2012) How reliable are Hounsfield-unit measurements in forensic radiology? Forensic Sci Int 220:219-223. https://doi.org/10.1016/j.forsciint.2012.03.004

27. Gremse F, Krone O, Thamm M et al (2014) Performance of lead-free versus lead-based hunting ammunition in ballistic soap. PLoS One. https://doi.org/ 10.1371/journal.pone.0102015

28. Thomas VG (2013) Lead-free hunting rifle ammunition: product availability, price, effectiveness, and role in global wildlife conservation. Ambio 42:737745. https://doi.org/10.1007/s13280-012-0361-7

29. Gascho D, Zoelch N, Schaerli S (2019) Explanation for the contradiction between the results of Diallo et al. (doi:10.1016/j.jofri.2018.10.001) and Winklhofer et al. (doi:10.1097/RLI.0000000000000032) in differentiating ferromagnetic from nonferromagnetic bullets by means of the dual-energy index. J Forensic Radiol Imaging. https://doi.org/10.1016/j.jofri.2019.100351

30. Reginelli A, Russo A, Maresca D, Martiniello C, Cappabianca S, Brunese L (2015) Imaging assessment of gunshot wounds. Semin Ultrasound CT MR 36:57-67. https://doi.org/10.1053/j.sult.2014.10.005

31. Serraino S, Milone L, Picone D, Argo A, Salerno S, Midiri M (2020) Imaging for ballistic trauma: other applications of forensic imaging in the living. In: Lo Re G, Argo A, Midiri M, Cattaneo C (eds) Radiology in Forensic Medicine: from Identification to post-mortem imaging. Springer International Publishing, Cham. https://doi.org/10.1007/978-3-319-96737-0_15

32. Decker SJ, Braileanu M, Dey C et al (2019) Forensic radiology: a primer. Acad Radiol 26:820-830. https://doi.org/10.1016/j.acra.2019.03.006

33. Cascini F, Polacco M, Cittadini F, Paliani GB, Oliva A, Rossi R (2019) Postmortem computed tomography for forensic applications: a systematic review of gunshot deaths. Med Sci Law 60:54-62. https://doi.org/10.1177/ 0025802419883164

34. Gascho D, Tappero C, Zoelch N et al (2019) Synergy of CT and MRI in detecting trajectories of lodged bullets in decedents and potential hazards concerning the heating and movement of bullets during MRI. Forensic Sci Med Pathol 16:20-31. https://doi.org/10.1007/s12024-019-00199-y

\section{Publisher's Note}

Springer Nature remains neutral with regard to jurisdictional claims in published maps and institutional affiliations.

\section{Submit your manuscript to a SpringerOpen ${ }^{\circ}$ journal and benefit from:}

- Convenient online submission

- Rigorous peer review

- Open access: articles freely available online

High visibility within the field

- Retaining the copyright to your article

Submit your next manuscript at $\boldsymbol{\sim}$ springeropen.com 